\title{
Diet and lifestyle assessment of patients suffering from diabetic nephropathy
}

\author{
GAYATRI BISWAL, CHANDRASHREE LENKA AND SONALI TRIPATHY
}

Received: 28.04.2016; Revised: 11.05.2016; Accepted: 23.05.2016

See end of the paper for authors' affiliations CHANDRASHREE LENKA Department of Home Science, P.G.T.D. Home Science, Ramadevi Women's University, BHUBANESWAR (ODISHA) INDIA Email : lenkachandrashree@yahoo. com
ABSTRACT : Diabetes is a disease in which either pancreas does not make enough insulin or there is insulin resistance, so that the glucose is unutilized by the liver, muscle and fat tissue properly. With diabetes for longer period of time the small blood vessels (micro) in the body are injured. When the blood vessels in the kidneys are injured, kidneys can not clean blood properly. Body will retain more water and salt than it should, which results in weight gain and ankle swelling which may have protein in urine. This may lead to diabetic nephropathy. The overall objective of this study was to asses diet and life style of the patients suffering from Diabetic Nephropathy. A cross-sectional study was carried out on 100 Diabetic people with nephritic syndrome. The study carried out by investigating patient's family background, medical past history, physical examination, nutritional and lifestyle assessment, physical activity assessment, medical and nutritional problems associated with the help of interview cum questionnaire method. The results of the study revealed that majority of the respondents had diabetes with Chronic Kidney Disease (CKD) and were suffering from Chronic Energy deficiency BMI. Fatigue and odema were the common symptoms found among most of the respondents. Starchy, spicy and too much sweet food was preferred by the patients. Taking 2-3 litres of soft water per day was observed among the respondents. Cereals, pulses, fats and oil, Milk and salt consumption was found to be less in comparison RDA in both male and female respondents which may be due to their ill health and dietary restriction. A positive trend was found in maintaining active style, taking regular diet and regular medicine and doing regular health check up among majority of the respondents which may be due to the impact of education, urbanization and mass media. Thus it can be suggested that controlling diabetes with high blood pressure, restricting protein and salt in the diet and maintaining active life style may be a solution to this problem.

KEY WORDS: Chronic kidney disease (CKD), BMI, RDA, Life style odema

- HOW TO CITE THIS PAPER : Biswal, Gayatri, Lenka, Chandrashree and Tripathy, Sonali (2016). Diet and lifestyle assessment of patients suffering from diabetic nephropathy. Asian J. Home Sci., 11 (1) : 213-219, DOI: 10.15740/HAS/AJHS/11.1/213-219. 